\title{
Esto no es una casa. La casa sin salida en el cine de Roman Polanski
}

\author{
Manuela RodRÍGUEZ DE PARTEARROYO \\ Departamento de Filología Italiana \\ Universidad Complutense de Madrid \\ manuelapartearroyo@gmail.com
}

Recibido: $13 / 09 / 2013$

Modificado: $31 / 03 / 2014$

Aceptado: 25/04/2014

\section{Resumen}

Desde sus orígenes, el cine de Roman Polanski ha mantenido intacto su poder de fascinación sobre el espectador cinematográfico, tanto por su incansable modernidad, como por la inevitable polémica que siempre arrastran sus películas. En este caso, pretenderemos acercarnos a dos comedias, escasas en su filmografía, como son What? (1972) y Carnage (2011), muy distantes en el tiempo aunque con interesantes coincidencias temáticas y narrativas. Nuestro interés primordial será ahondar en su retrato de las figuras femeninas de ambas obras y su ubicación, física y metafórica, en el espacio de la casa. Siguiendo la estela de maestros como Luis Buñuel, Marco Ferreri o Stanley Kubrick, Polanski encerrará a sus mujeres en un refugio hostil y sin salida para que vaya cayéndose progresivamente la máscara de la sociedad moderna, dejando salir, poco a poco, al animal primitivo que nunca hemos dejado de ser. Esto no es una casa, sino una balsa llena de náufragos tratando de sobrevivir.

Palabras clave: Polanski, refugio, máscara, salida.

Title: This is not a House. The home with no exit in the films of Roman Polanski.

\section{Abstract}

Since his very first works, Roman Polanski has been able to maintain intact a powerful fascination in the film spectator, not only due to his inexhaustible modernity, but also because of the unmistakable controversy that his movies always acquire. In this case, we will focus on two comedies, What? (1972) and Carnage (2011), which are chronologically quite distant but that carry interesting thematic and narrative coincidences. Our interest will be to delve into his portrayal of the female characters in both films, and their subsequent physical and metaphorical location in the space of the house. Following the trace of masters like Luis Buñuel, Marco Ferreri or Stanley Kubrick, Polanski will enclose his women in a hostile refuge with no exit where we will witness the fall of modern society's mask, where they will let loose the primitive animal we have never stopped being. This is not a house, but a raft of shipwrecked trying to survive.

Keywords: Polanski, refuge, mask, exit. 


\section{Índice}

1. De cómo Godot estaba escondido en una villa italiana

2. El Dios de la Apariencia

3. La mujer, quimérica inquilina

4. El discreto encanto de las casas sin salida

La filmografía de Roman Polanski tal vez represente el discurso más heterogéneo y atormentado del cine de las últimas décadas. Este director inclasificable y siempre polémico ha sabido reinventarse incansablemente, a través de los más variados géneros cinematográficos, y siguiendo tan sólo la estela de un cine profundamente provocador. A lo largo de sus treinta y cinco cintas y sus casi sesenta años en activo, el cine de Polanski es una fuente incesante de modernidad. Este artículo ha preferido acudir a la parte menos analizada de su filmografía, la comedia, donde encontramos, además de la magnífica Dance of the vampires (1967), dos obras que resultan enormemente interesantes: What? (1972), comedia rodada en Italia bajo el amparo de Carlo Ponti, y Carnage (en español Un dios salvaje, 2011), penúltima obra del director hasta la fecha. Dos películas dispares con respecto al Polanski paradigmático, que, sin embargo, participan de sus principales obsesiones cinematográficas, y que, además, guardan entre sí sorprendentes convergencias.

El presente artículo pretende acercarse, a través de estas dos comedias, a un espacio fundamental del universo polanskiano, la casa, donde habitan algunos de sus más profundos fantasmas, identificados a menudo con la figura de la mujer. La casa como refugio nuclear se transforma en el cine de Polanski en su reverso oscuro, en un espacio de paranoia, peligro e inquietud, donde siempre acaba apareciendo lo salvaje de nosotros mismos.

\section{De cómo Godot estaba escondido en una villa italiana}

What? o ¿Qué? (1972), ya desde su mismo título, invita a la incertidumbre. Tal vez sea el secreto mejor guardado en la amplia filmografía de ese maestro atormentado que es Roman Polanski ${ }^{1}$. Trataremos de desvelar algunas pistas de este filme injustamente incomprendido. Salvo excelsas excepciones ${ }^{2}$, la compleja ironía de What? no gozó de una recepción afortunada, tal vez enjuiciada sin la libertad creativa de años precedentes, o determinada por los trágicos

\footnotetext{
1 Aludimos implícitamente al título de la obra de Diego Moldes (2005), Roman Polanski. La fantasía del atormentado.

2 Mencionaremos el caso del célebre crítico Giovanni Grazzini, que valoró la película como "el mejor Polanski y ciertamente el más apetitoso" (apud Moldes 2005: 251). Hay que precisar que la película en Italia gozó de un éxito inusitado, en comparación con otros países. No olvidemos que el filme estaba rodado y producido en Italia, y protagonizado por una estrella del calibre de Marcello Mastroianni.
} 
momentos por los que pasaba la vida personal del director ${ }^{3}$. De hecho, What? resultó un proyecto significativo para Polanski no tanto por su implicación creativa, sino por el desahogo mental que le produjo.

El rodaje de What?, así como los años pasados en Italia después del estreno del film, representaron para Polanski, según propia confesión, un intermedio feliz de dolce vita que le trajo la calma y le permitió volver a llevar una existencia normal. El film refleja algunos aspectos de su vida personal después de los crímenes de la familia Manson: una huida a una sexualidad lúdica, y el trato con la jet set internacional, algunos de cuyos miembros fueron contratados para el film. (Avron 1990: 128)

La película abre con una escena de coche, noche cerrada. Nancy (Sydne Rome), una hermosa y naïve americana, está a punto de ser violada por quienes la han recogido en auto-stop. Consigue escapar, pero sin equipaje, tan sólo aferrada a su inseparable diario, llega a una hermosa villa italiana donde es confundida con alguien al que se espera (¿Godot?). Nancy es guiada a una habitación y se acuesta, con la extraña sensación de que es observada. A la mañana siguiente, Nancy descubre que le han robado la ropa, por lo que se ve obligada a taparse con lo que primero encuentra, y acto seguido, se presenta medio desnuda en el porche de la casa. Allí va conociendo a los extraños habitantes de esta posada nudista, que viven obsesionados por el sexo, la comida, los ruidos amenazantes y el ping pong. El primero es Alex (Marcello Mastroianni), un ex-proxeneta, sobrino del dueño, que establece en seguida una cómica (aunque a veces tenebrosa) relación sadomasoquista con Nancy. Luego aparecen los tres habitantes de la azotea, Jimmy, Tony y el otro sobrino del anfitrión, Mosquito (el propio Polanski), que viven dominados por sus necesidades biológicas, en un infantilismo grotesco de arpones, sexo desenfrenado y vacío. Luego está el personaje interpretado por Romolo Valli, amante de Mozart, las flores y las mujeres, en ese orden; y por supuesto, Noblart, el anfitrión (Hugh Griffith), un viejo inválido, coleccionista y voyeur, acostumbrado a poseerlo todo ${ }^{4}$. Nancy convive unos días con estos extraños huéspedes y va cayendo en la cuenta de que todo lo que vive es una especie de déjà $v u$, una copia casi exacta de la noche anterior. Pronto, el viejo se encaprichará con Nancy y le pedirá que lo

\footnotetext{
${ }^{3}$ Recordemos que el film es del año 1972, tan sólo tres años después del terrible crimen de Charles Manson y La Familia. Polanski era por entonces perseguido por la prensa de todo el mundo.

4 El apellido del anfitrión fusiona los términos noble y art, que describen irónicamente, como veremos, sus perversiones de coleccionismo y excitación por la posesión.
} 
visite en su aposento. En un voyeurismo in crescendo le irá pidiendo que le muestre partes de su cuerpo más y más íntimas, a lo cual ella accede por ser el deseo de un moribundo. Precisamente cuando Noblart toca su cuerpo, muere fulminantemente. El clímax absurdo del filme comienza entonces. Nancy se asusta y sale corriendo. Los huéspedes, sin saber muy bien por qué, comienzan a perseguirla, y ella, completamente desnuda, se lanza de nuevo a la carretera y deja la casa. Alex, que por fin había encontrado una compañera de fantasías, le pregunta por qué se va y Nancy, en un alarde de absurda inteligencia, rompe el pacto de ficción y responde que si no se fuera, no podrían terminar la película. A lo cual, un estupefacto Mastroianni, y con él, nosotros los espectadores, grita: "¿Qué?".

Así termina esta comedia absurda, donde el imperante machismo de todos los personajes masculinos resulta tan exagerado, tan grotesco y satírico, que nos parece otra más de las mordaces críticas de Polanski. Será esa absurda heroína femenina quien consiga poner en entredicho la disparatada libido de esa galería de machos grotescos que danzan por la villa italiana.

Almost in its own accord, our screenplay turned into a ribald, Rabelaisian account of the adventures of a fey, innocent girl, wholly unaware of the sort of company that surrounds her in a weird Riviera villa inhabited exclusively by phalocrats. (Polanski 1984: 344 )

Se trata por tanto, del viaje a ninguna parte de una ingenua muchacha, que se instala en una extraña villa llena de "falócratas", tal y como los apoda el propio Polanski. No podemos olvidar que el productor de este filme es Carlo Ponti, pero la producción del filme inmediatamente anterior de Polanski, Macbeth (1971), había corrido a cargo de Hugh Hefner y la todopoderosa Playboy. ¿Acaso es una coincidencia? De hecho, según el propio Polanski, su intención era reírse del lujo desmedido de esos tiempos: "What? [...] somehow reflected the absurdity and extravagance of the outgoing sixties" (Polanski 1984: 343-344). No nos extrañaría que Polanski escribiera imaginando una villa infernal y paradisíaca a la vez, donde el tiempo, el sexo y el coleccionismo fuesen compañeros de viaje, como si Godot se hubiera escondido entre los rincones, espiando tras las rendijas y viviendo una espera eterna y repetitiva.

A primera vista parece una comedia erótica de ésas que tuvieron un breve apogeo a principios de los setenta, un tipo de cine ignorante de las crecientes desigualdades que acabarán de estallar a fines de la década: 
La forma narrativa abierta favorece también la descripción sociológica de un modo de vida ligero e inmoral (pero sin embargo falocrático), característica de una época despreocupada, todavía no alcanzada por los grandes desastres económicos de los años 70. (Avron 1990: 128)

Sin embargo, detrás de tanto absurdo aparentemente trivial, está la mirada siempre oscura de Polanski que muestra en What? su rostro más descarado para reflexionar acerca de los tabúes sexuales de la dominante sociedad burguesa ${ }^{5}$. En esta villa godotiana imperan, con poderosa constancia y sin pretendidos enmascaramientos, el machismo y la intolerancia más evidentes, tanto entre los mismos huéspedes como con respecto a la recién llegada.

Queríamos hacer hincapié, además, en el matiz "extranjero" de la mayoría de los personajes de la villa. El cine de Polanski reflexiona sobre el ambiente hostil, pero también sobre el efecto que éste ejerce en el extranjero, en el emigrante, en el recién llegado, algo que podríamos conectar sin problema con la biografía del cineasta, con su propia condición de expatriado. Nos parece relevante añadir a Nancy a la lista de emigrantes forzados que han protagonizado su cine. Desde la oscuridad de Trelkovski en Le locataire (1976), hasta la angustia del doctor Walker en Frantic (1988), ambas por las calles de París, pasando por la agonía de Catherine Deneuve en el Londres de Repulsion (1965), el simpático autoestopista que invitan al yate de Nóz $w$ wodzie (El cuchillo en el agua, 1962), la campesina Tess (1979), perdida y sola en un mundo de nobles, o, claro está, el propio Pianista (2002), sin duda el más doloroso representante del desplazamiento. En What? muchos de los personajes son extranjeros (británicos, italianos, franceses, y, por supuesto, la estadounidense Nancy), y todos ellos habitan esta extraña casa al amparo del viejo Noblart sin atisbo de movilidad, estacionados en su absurda indolencia, desconectados del mundo y de sí mismos. Allí aparece Nancy, turista extranjera también perdida en un mundo que, simplemente, no tiene sentido más allá de sí mismo. No en vano, el filme ha sido repetidamente relacionado con Alice in Wonderland de Lewis Carroll ${ }^{6}$, la mujer viajera por excelencia.

Así pues, al modo de Rabelais, como bien comparaba el propio Polanski, se genera en la villa algo parecido a una sociedad, un microcosmos sin salida, donde están representados un abanico de locos y la colección más completa de disparatadas psicopatías sexuales vistas en el cine, lo cual enturbiará la estancia de la ingenua

${ }^{5}$ Resulta interesante comentar los paralelos de crítica a la sociedad adinerada, hedonista y frustrada de los años sesenta que también observamos en la reciente serie de AMC, Mad Men.

6 Para mayor información acerca de esta influencia, vid. Moldes (2005), Avron (1990) y Feeney y Duncan (2006). 
intrusa. Ahí está otra de las características fundamentales del grotesco, no sólo se genera un modelo hiperbólico que invita a una crítica social, sino que, para que semejante modelo se sostenga, es preciso generar todo un mundo nuevo de jerarquías.

Come sempre con il grottesco, non si tratta solo di costruire una satira di costume che miri alla critica puntuale dell'attualità. Si tratta d'altro, di lasciare emergere, attraverso il ritratto carico di una situazione determinata, un'immagine generale che colga il senso grottesco (cioè la verità inverosimile) della vita sociale. È la commedia grottesca della società [...]. (Gaetano 1999: 62)

La comedia grotesca de la sociedad. Vemos cómo la estética grotesca impregna cada elemento, cada personaje y cada espacio, no sólo construye una situación cómica, sino que fabrica toda una sociedad que debe tener sentido en sí misma, sin necesidad de verosimilitud con respecto al mundo exterior. Esto nos lleva al "grotesco apocalíptico"7 de Marco Ferreri, cuyas historias siempre parecen sumergirse en estos mundos sin salida, sirvan de ejemplo $L a$ grande bouffe (1973), Dillinger è morto (1969) o Ciao maschio (1978). El desvarío y el absurdo son constantes, pero dado que todos los elementos de la narración tienen sentido en el pequeño microcosmos que genera la historia, resulta sostenible. Tal vez el hecho de que What? esté interpretada por Mastroianni facilite la conexión entre ésta y las obras de Ferreri, que en ese año 1972 estrena Liza, protagonizada también por Mastroianni. Vemos los ecos de su cine, $y$, tal vez también el imaginario del dibujante Milo Manara, muy cercano a todos ellos (Moldes 2005: 254). Así pues, dejándose impregnar por el erotismo de tintes grotescos, Polanski abraza caminos absurdos que nos acercan, también, a los sueños surrealistas de Luis Buñuel. Todo tiene un precio, desde la habitación que salva a Nancy del primer asalto sexual, hasta su más íntima dignidad, que deja al descubierto para que el moribundo pueda poseer la obra de arte definitiva, un tableau vivante que, para bien o para mal, le llevará a la muerte ${ }^{8}$. El ansia por coleccionar es el ansia de poseer, lo cual no deja de ser un sustituto del placer sexual:

\footnotetext{
7 Término acuñado por Gaetano en el ensayo sobre el grotesco en el cine italiano, II corpo e la maschera, el cual titula su capítulo dedicado a Ferreri como "L'Apocalisse Grottesca".

${ }^{8}$ Diego Moldes apunta acertadamente que la secuencia en que Noblart toca el sexo de Nancy representa su extremaunción, la catarsis de su voyeurismo y, tal vez, su despedida del mundo (Moldes 2005: 257). Nancy, cuya juventud y vitalidad es excepcional en contraste con el resto de huéspedes, parece convertirse casi en un ángel de la muerte.
} 
Por un lado, What? evoca la mediocridad de los regateos que gobiernan el mercado del arte; por otro lado, este film reafirma la preocupación de los artistas de excitar con sus obras no sólo el sentido estético sino también el sentido erótico de los hombres. "El valor comercial del arte reside en su capacidad de suplir la estimulación directa del erotismo. En What?, todas las formas del arte se desvelan como unos sustitutos del placer sexual", escribe V. Wexman. Y el placer sexual el más fuerte, el que provoca el voyeurismo de la carne, desemboca en la muerte. Disfrutar del espectáculo (cinematográfico) hasta morir. (Avron 1990: 128-129)

Y es que, más allá de la estimulación erótica del arte, y la fascinación fetichista, casi artística, del erotismo, se trata de un mundo de angustia, de paranoia, del que no se puede salir, muy propio del universo polanskiano. El surrealismo apoya el absurdo en unas connotaciones oníricas donde se hacen patentes los fantasmas, y aquí, Polanski nos relata, bajo la apariencia de un cuento desinhibido, la angustia de una sociedad obsesionada por el desahogo sexual y la posesión mercantil, sin tiempo y sin memoria. Godot en estado puro.

\section{El Dios de la Apariencia}

Dejamos atrás el artificio de What? y viajamos casi cuarenta años hacia adelante, hasta el estreno de Un dios salvaje (Carnage) en 2011. Se trata de una nueva incursión de Polanski en la comedia, lo cual, como hemos dicho, resulta más bien escaso en su filmografía. Se trata de una deliberada tragicomedia en la que Polanski saca a relucir, de nuevo, la parte salvaje del ser humano, la huida de las convenciones y la explosión de los instintos. Asistimos, por tanto, al desvelo de las verdades de dos parejas que se han citado amigablemente para solucionar un conflicto entre sus hijos. Según parece, el hijo de los Cowan (Cristoph Waltz y Kate Winslet), los visitantes, ha agredido al de los Longstreet (John C. Reilly y Jodie Foster), los anfitriones, lo cual ha resultado en una crisis escolar que se disponen a resolver de modo civilizado. Sin embargo, la tensión se irá agudizando y la cortesía dará paso al dios salvaje que reside en cada uno de ellos, haciendo que el espectador se cuestione "la normalidad" en una sociedad plagada de máscaras y apariencias.

Polanski hace su filme más teatral, no sólo por estar basado en la obra de Yasmina Reza (2007) Le dieu du carnage, estrenada en 2008 y llevada con gran éxito a los escenarios de todo el mundo ${ }^{9}$; sino porque Polanski no escapa a la claustrofobia que producen las adaptaciones teatrales en la pantalla, al contrario, parece dar la

${ }^{9}$ En España también gozó de un gran éxito de público y crítica, fue estrenada en el teatro Alcázar en el mismo 2008, protagonizada por Aitana Sánchez-Gijón, Maribel Verdú, Pere Ponce y Antonio Molero. 
bienvenida al desafío de contar la historia sin salir de una habitación. La sombra del mejor cine planea sobre Polanski, la referencia a El ángel exterminador de Buñuel (1962) resulta inevitable, tanto por su asfixiante negación de exterioridad, como por la progresiva pérdida de papeles de sus protagonistas ${ }^{10}$. Igual que en el caso de los náufragos burgueses de Buñuel, el protocolo va cayendo en picado en favor del instinto y se van desenmascarando las apariencias. La verdad humana que se cuela por las rendijas de la máscara de la burguesía contemporánea. Así lo explica Longworth (2011) en su artículo sobre el filme: "Artificial politesse gives way to passive aggression, which gives way to aggressive aggression between the couples and within them". La tensión dramática está servida. La potencia del teatro parece impregnar la pantalla de Carnage, el naturalismo que supuestamente resulta tan necesario para el cine parece haber perdido la batalla ante la potencia emotiva de la gesticulación teatral. De hecho, según desvela la actriz Jodie Foster (en Polanski 2012), que interpreta a Penelope Longstreet, Polanski les instaba precisamente a perder naturalidad, a buscar la artificialidad en sus interpretaciones: "I think Roman's directions to everybody were to be more phony, more phony more phony. Could you be more fake?".

Jugando a exagerar la vida misma, a ser más teatrales, Polanski insta a sus actores a ir en busca, tal vez, de un enfoque grotesco que remueva las conciencias del espectador hasta provocarle la más dolorosa de las carcajadas. Precisamente, una de las cosas que más sorprendía tanto a Reza como a quienes han representado Le dieu du carnage era precisamente que la gente se reía a carcajadas ante semejante drama humano. Un panorama grotesco y sin embargo verosímil, latente en nuestra sociedad de hoy, una auténtica tragedia que, contada en clave de farsa, consigue que el espectador se mire al espejo cóncavo que ofrece la obra, y asuma de modo lúdico una dolorosa verdad ${ }^{11}$. No nos extrañaría que Polanski pretendiera exagerar para hacer ver al espectador en qué se ha convertido nuestra sociedad, pintando de modo más grotesco algo que está ahí, en nuestro mundo, una crítica palpable y poco disimulada al mundo de hoy. Ya lo decía Bergson en su ensayo sobre la risa:

\footnotetext{
${ }^{10}$ Posterior a What?, también se estrenará otro clásico de casas sin salida, como es El Resplandor de Kubrick (1980), otro maestro por el que Polanski ha mostrado admiración en varias ocasiones.

${ }^{11}$ Aludimos al concepto de espejo cóncavo conscientemente, pues esta estrategia de distorsión de la realidad nos recuerda inevitablemente al esperpento valleinclaniano.
} 
La risa es, ante todo, una corrección. Hecha para humillar, debe causar en la víctima una impresión dolorosa. La sociedad se venga así de las libertades que se han tomado con ella. La risa no alcanzaría su objetivo si llevase la marca de la simpatía y la bondad. (Bergson 2011: 118)

En la crítica contemporánea al estreno, Luis Martínez alude a esta extraña mezcla de risa y horror, de carcajada grotesca, de disparate repugnante y cómico, aludiendo a la imagen del vómito de Nancy como materialización física de las mentiras que acumula en su interior el individuo contemporáneo, que, un día, revientan de modo indiscriminado, imposible de disimular:

Y no es metáfora. En un momento determinado [...] Kate Winslet arroja todo lo que es capaz de acumular su estómago (y es mucho) sobre la mesa del salón comedor. Justo en ese instante es imposible detener la risa, una risa que se confunde con una extraña sensación de horror. Hemos llegado, Polanski es Polanski. [...] tensar la cuerda hasta el momento exacto en el que es imposible determinar a qué obedece el hormigueo del estómago: ¿es la risa o la náusea? (Martínez 2011)

Risa y náusea a partes iguales. La vida servida en un plato de repugnante crudeza que, sin embargo, nos produce carcajadas. Reír por no llorar, claro. Para explicar semejante despliegue de recursos grotescos, Martínez recurre a un mito fundamental del siglo XX, la metamorfosis de Gregor Samsa, que no por casualidad refleja esa distorsión progresiva de la realidad hacia caminos tan críticos como cómicos, sino también la animalización en todo su esplendor, la materialización definitiva de los tormentos del individuo social, una vez destapada la caja de los truenos.

Cuenta Yasmina Reza que conoció a Polanski 20 años atrás mientras preparaba una versión teatral de La metamorfosis de Kafka. Todo encaja. La película, en realidad, no es más que el "monstruoso insecto" que imaginara el checo: tan cruel y patética como divertida. [...] Los usos y costumbres de unos tiempos que unos Ilaman modernos y otros simplemente vomitivos son desnudados con una brillantez sólo antes contemplada en gente como [...] Woody Allen. (Martínez 2011)

Nada más angustioso que el salvaje y desolador proceso de metamorfosis del individuo representado por la figura de Samsa, la máscara que nos impide ver nuestra cruel pérdida de humanidad, el proceso de desintegración de todo lo humano, debido, precisamente, al exceso de elementos sociales superfluos. Los Cowan y los Longstreet aparecen disfrazados de individuos civilizados, y van sufriendo una metamorfosis progresiva hacia la animalidad, hacia el 
instinto que nunca ha dejado de flotar bajo la superficie de la máscara. Así, Michael Longstreet dirá: "My wife has dressed me up as a liberal, but the fact of the matter is I don't have patience for this touchy feeling bullshit. I am a short tempered son of a bitch, ok?" (Polanski, dir., 2011).

Y así, la convivencia cívica, la búsqueda de una solución ante un caso de violencia infantil se va perdiendo en favor de la verdad, ésa que casi nunca sale a la luz, esa que duele reconocer. Precisamente Penelope, la buena samaritana, la más insistente en reivindicar el porqué de la mala acción, acaba dando su brazo a torcer diciendo: "Doing the right thing is futile. Honesty is stupid" (Polanski, dir., 2011). El dios salvaje, más descarnado que nunca.

\section{La mujer, quimérica inquilina}

Conectamos, por tanto, dos elementos fundamentales en el imaginario de Roman Polanski. Por una parte tenemos el espacio del refugio, la casa, que en el cine del polaco se ve generalmente convertido en espacio amenazante y hostil. Desde el castillo de El baile de los vampiros y el yate de El cuchillo en el agua, pasando por la casa llena de ojos de Repulsión, o los ojos del quimérico inquilino en la casa de Isabelle Adjani; hasta llegar, cómo no, al refugio inestable del gueto de Varsovia en El pianista. Antítesis por excelencia de la casa-refugio-nido que propugnaba Gaston Bachelard en su Poética del espacio (Bachelard 2000: 27-52), estas casas polanskianas serán firmes constructoras de la tensión narrativa de sus películas, casas sin un ápice de comodidad y calma, auténticos no-refugios.

Dentro de este espacio de angustia tiende a "refugiarse" siempre una figura femenina. Una mujer, figura tradicionalmente conectada al espacio de la casa que Bachelard considera clave para el equilibrio hogareño:

Parece que la casa luminosa de cuidados se reconstruye desde el interior, se renueva por el interior. En el equilibrio íntimo de los muros y de los muebles, puede decirse que se toma conciencia de una casa construida por la mujer. Los hombres sólo saben construir las casas desde el exterior, no conocen en absoluto la civilización de la cera. (Bachelard 2000: 76)

Bachelard revela cómo en el imaginario de la casa, la luz la genera la figura de la mujer, lo cual es exacto en la filmografía de Polanski, quien coloca a sus protagonistas en la intimidad de su refugio, justo antes de romper su protección con la aparición de algún elemento ajeno que produce el advenimiento de la hostilidad. Ahí está la luminosidad de Catherine Deneuve en Repulsión, la fragilidad de Mia Farrow en La semilla del diablo, la dulzura de Sharon Tate en 
el castillo de El baile de los vampiros, o la ingenuidad de Isabelle Adjani en El quimérico inquilino. Todas ellas habitan el hogar que está a punto de convertirse en una prisión, combinando una potente feminidad con un latente tormento que ha estallado, o está a punto de estallar. En What?, la visitante se integra con extrañeza en el espacio de la villa, siendo ella una de las pocas féminas entre los huéspedes (exceptuando a la rígida enfermera alemana de Noblart y la pareja de francesas nudistas que tan sólo hablan entre sí). Nancy nunca acaba de estar cómoda en ninguna parte, revolotea por las estancias conociendo a los distintos huéspedes, con una curiosidad que a menudo termina con una fuga. Por su parte, Carnage nos brinda dos figuras femeninas, interesantes polos opuestos de la mujer de hoy; una visitante, otra huésped. Veremos con detenimiento algunas de sus diferencias.

Resulta inevitable recurrir al concepto de corporalidad para observar la concepción que tiene Polanski de la mujer. Como punto de partida tenemos el caso de What?, donde la mujer es un objeto puramente erótico que, sin embargo, parece esconder unas cuantas respuestas críticas a ese machismo dominante en la sociedad que, creemos, Polanski pretendía censurar. Por otro lado están Nancy ${ }^{12}$ y Penelope, las dos madres de Carnage, representantes, o tal vez consecuencias, de un nuevo modelo de mujer aparentemente alejado de la turista americana de What? En principio, Carnage nos desvela una sociedad nueva, donde la mujer emancipada parece haber encontrado su papel en la sociedad de modo más estable. Sin embargo, progresivamente se van desenmascarando las desigualdades que aún sufre la mujer tras el triunfo del neoliberalismo, una mujer que sigue luchando cotidianamente con sus preocupaciones vitales, compatibilizando su papel de mujer profesional con el tradicional de madre y esposa, y hacerlo sin perder por el camino tantos compromisos de solidaridad y cortesía que le son obligatorios en la sociedad del bienestar. Todas esas preguntas se las hace Yasmina Reza, otra exitosa mujer del siglo XXI, y las recoge la mirada tormentosa de Polanski sin aportar respuestas definitivas, sino más bien recuperando las esencias de lo primitivo, para devolver cordura a la mascarada de fingimientos del mundo actual.

Al hablar de What?, partimos de un modelo de mujer puramente objetual, de hecho, creemos que la obra de Polanski va más allá del mero entretenimiento erótico y fabrica una auténtica

12 Resulta francamente curioso que Nancy vuelva a ser el nombre elegido por el director, el mismo que el de la protagonista de What? Polanski sustituyó el nombre de la obra original, Annette, por resultarle excesivamente europeo, según ha desvelado en las entrevistas (en Polanski 2012) acerca de su adaptación al cine en colaboración con la propia Jasmina Reza. 
defensa del cuerpo. Es una película sensorial a todas luces, donde el sujeto retorna a su estado más animal, y tal viaje hacia lo primitivo no sólo afecta a los disparatados falócratas de la villa, sino también al espectador, que queda noqueado ante semejante ausencia de narratividad: "En lugar del principio, nudo y final tradicionales, sólo habría sensaciones" (Sandford 2009: 180).

Polanski contrapone dos tipos de obra de arte. Por un lado está la obra artística, los objetos que colecciona Noblart, los que busca Mosquito bajo el mar, o la misma película en sí, que también es obra de alguien. Por otro está la obra de arte que es el cuerpo, encarnado en la sensualidad de Nancy y en la obsesión que provoca en los huéspedes de la villa. De hecho, desde la primera noche, la turista pasa a ser un puro objet d'art, una obra para la contemplación, para lo cual enseguida se ve obligada a prescindir primero de su equipaje, luego de su ropa, y finalmente de sus tabúes sexuales. Huye de la casa, subida a un camión, completamente desnuda pero firme en su decisión, dejándonos a todos atónitos, desnudos de convencionalismos. Era precisamente esta cuestión de la desnudez la que había motivado a Polanski a realizar el proyecto: "Después de Macbeth, la idea de un script erótico basado en la simplicidad de la desnudez perseguía a Polanski" (Avron 1990: 128). A Nancy se le roba su identidad hasta convertirla en un objeto preciado.

Así, el cuerpo es obra de arte que se contempla, pero es también objeto que se desea tocar. "El placer de Noblart, el viejo chivo, es el placer de la mirada, el del voyeur, por eso colecciona obras de arte, para contemplarlas con su repugnante sentido posesivo" (Moldes 2005: 257) ${ }^{13}$. Ahora bien, Noblart dice que ha abandonado su labor de coleccionista para comenzar a apreciar obras tangibles. Nancy es esa obra tangible. Tocar es tener, y por tanto poseer, convertir en un objeto. Igual que La Balsa de la Medusa, su belleza no es cuestionable, pero sí tiene un precio. Así, Polanski contrapone la simplicidad que reside en la desnudez e ingenuidad de Nancy, y el ansia de posesión de los huéspedes de la villa. De algún modo, nos narra la transición entre una sexualidad pura hacia una sexualidad cargada de connotaciones de poder, materializando la perversión del mundo mercantil. Como dice Buci-Glucksmann, "les scénarios du corps fémenin métaphorisent ceux du corps merchandise" (Buci-Glucksmann 1986: 413).

La mujer, como cuerpo, en su desnudez, tiene para Noblart y para el resto de obsesos falócratas el atractivo de la mercancía. Un paseo de la mano de Walter Benjamin nos ilumina para explicar el sentido de este sex appeal de lo inorgánico que es la mujer en el

13 Polanski nunca ha negado su voyeurismo cinematográfico. Detrás del erotismo imperante de What? hay un director obviamente voyeur, pero también hay una mirada morbosa en Carnage, aunque sea un voyeurismo más moral. 
mundo mercantil. "La libération sexuelle des femmes sous le régime capitaliste a eu l'effet cauchemardesque de donner à toutes les femmes la liberté d'être des objets sexuelles (pas des sujets)" (BuckMorss 1986: 386). Así, la liberación sexual le ha dado a Nancy la paradójica libertad de convertirse en objeto, a merced de la sociedad capitalista. La mujer se transforma en muñeca. Nancy la muñeca ${ }^{14}$.

Ironiquement, si les enfants, au début, jouaient avec les poupées afin d'apprendre à se comporter d'une manière parentale et adulte, c'està-dire humaine, ce jeu est devenu le terrain d'apprentissage d'un comportement reifié. Le but des petites filles maintenant est de devenir une poupée. [...] machines qui promettent la naturalisation de I'humanité et I'humanisation de la nature ont abouti en fait à la mécanisation des deux. (Buck-Morss 1986: 388)

No nos parece casual que Polanski fabrique a Nancy con el modelo de la muñeca en mente en un año como 1972, cuando el eco del movimiento feminista comenzaba a sentirse por fin en la sociedad occidental. Son muy conocidas las reivindicaciones de la vanguardia feminista durante la década de los setenta, donde brillan nombres como los de Martha Rosler, Hannah Wilke, Cindy Sherman o Valie Export. Precisamente en relación al concepto mujer/muñeca, Sherman ha fabricado la mejor parte de su opus artístico. Valga mencionar, por ejemplo, su obra Doll Clothes.

La película Doll Clothes [Ropa de Muñeca], muda y en blanco y negro, cuenta la historia de un fracaso, $[. .$.$] dando voz a la conciencia de$ que la artista sólo podrá autodeterminarse en su identidad de mujer y creadora si logra desarrollar estrategias que le permitan repeler el poder de la mano que la maneja. De lo contrario, su destino será el mismo que el de la muñeca. (Shor 2013: 18)

Nancy se cambia de ropa una y otra vez, porque los huéspedes se la quitan sin permiso, porque la desnudan o la disfrazan, intentando dominarla. Como si de una muñeca se tratase, Nancy se mecaniza hasta convertirse en un cuadro más de la colección de Noblart, aunque, en una venganza definitiva, es Nancy quien ejerce de ángel de la muerte. La muñeca se empodera y sale de la ficción en todos los sentidos: de la casa, del absurdo de la villa y de su

${ }^{14}$ En España, esta analogía entre el personaje de Nancy y la figura de la muñeca, juguete infantil por excelencia, guarda otra feliz coincidencia pues, como es conocido, "Nancy" fue el nombre de la popular muñeca lanzada al mercado por Famosa, que buscaba competir con la Barbie norteamericana. Polanski, sin embargo, era ajeno a esta irónica relación. 
condición de mujer objeto. La quimérica inquilina se rebela contra Godot y sale victoriosa, desnuda pero victoriosa ${ }^{15}$.

Tornamos ahora al caso de Carnage, cuarenta años después de What?, en una sociedad completamente distinta como es la Nueva York de principios del siglo XXI. Una sociedad del bienestar, virtual y veloz, donde la sobreprotección de los hijos y la prevención ante el dolor generan un microcosmos de artificialidad que, una vez explota, resulta aún más violento que la verdad. Es un mundo mucho menos desnudo que el absurdo godotiano de What?, pero no menos grotesco. Será interesante atender a la evolución de la mujer, si el movimiento feminista ha conseguido concienciar acerca de una sociedad más equilibrada entre géneros o si, por el contrario, el esfuerzo ha sido en vano. Es esencial preguntarnos por las diferencias entre Nancy Cowan y Penelope Longstreet. Dos mujeres en apariencia exitosas y felices, aunque de principios completamente divergentes. De hecho, la tensión Penélope-Nancy resulta fundamental en la obra, un enfrentamiento tal vez más profundo que el de los dos maridos, pues refleja la posición de la mujer con respecto a sí misma y con respecto a las convenciones de la sociedad.

Penelope es profesora y está acostumbrada a dominar las conversaciones. Siente una superioridad ética frente al resto de personajes por haber escrito un libro sobre el sufrimiento en África. Su hijo es el agredido, gracias a lo cual se ve en la cómoda posición de quien no ha errado en la educación de su hijo, atreviéndose a lanzar irritantes lecciones sobre cómo encauzar al descarrilado vástago de los Cowan. Está casada desde hace años, suponemos que por amor, con un hombre profesionalmente poco ambicioso. Michael es en el buen sentido de la palabra bueno. Además de ser el menos conflictivo de los cuatro, ha asumido una vida mediocre a la sombra de su mujer, pero también esconde un abanico de frustraciones que acaban saliendo a la luz, llegando incluso a aliarse con Alan en su batalla dialéctica contra Penelope. Curiosamente, éste último (que, recordemos, defiende a multinacionales farmacéuticas de litigios por negligencia médica), acaba diseccionando con cinismo y crueldad la silueta social de Penelope, diciendo:

Penelope, nobody cares of anything outside of themselves. Sure we all like to believe in some possible correction, one we could author ourselves, completely free of selfish considerations... Like you writing this book on Darfur, oh no, which I think is great... I understand how

15 Inevitable resulta la mención a La Venus à la fourrure (2013), último film de Polanski estrenado contemporáneamente a la redacción de este artítulo, una obra que viaja muy en paralelo con What?, otra casa sin salida, en este caso un escenario teatral, donde presenciamos la definitiva venganza antropológica de la mujer objeto convertida en diosa destructora. 
you might say: "Okay... I pick a massacre, as it is full, and I write a book. Everybody has to save themselves somehow". (Polanski, dir., 2011)

El caso de Nancy nos parece distinto, un modelo de mujer antagónico al de Penelope que, sin embargo, sufre similares dificultades y frustraciones. Es broker en Wall Street, una mujer de hoy que, sin embargo, resulta mucho menos reivindicativa. Se casó con un hombre mayor que ya había estado previamente casado, y parece dejarse dominar por él, por su dependencia del teléfono móvil, por su cinismo y su falta de interés por la familia. En las primeras escenas pretende dar por terminado el problema, ejerciendo un tímido segundo plano. Avergonzada por la constante interrupción de las llamadas telefónicas de Alan, pero ante todo tratando de ser conciliadora, de calmar las aguas entre la ortodoxia tardoprogresista de Penelope y el cinismo de su marido. Sin embargo, la escena en que Nancy vomita sirve como catalizador de las frustraciones, agravando la tensión no sólo entre ambas parejas, sino también entre maridos y esposas. El clímax llega cuando Nancy toma las riendas de su desequilibrio de poderes con Alan cuando le quita el móvil y lo sumerge en el florero. Entonces, vemos como Alan queda humillado, incluso físicamente, sentado en el suelo completamente derrotado.

De hecho, esto nos lleva a una conexión fundamental con What? La visión de la mujer no es completa hasta que la contrastamos con la perspectiva de la mujer que tiene el hombre, y cómo de ella nacen todas las máscaras de la sociedad. Aquí, de nuevo recurrimos a los cínicos latigazos de sinceridad de Alan, quien desde el principio desecha la superioridad moral de los Longstreet, pero aboga por una superioridad profesional, prestándole un mínimo interés a la solución del problema que los retiene, y tratando de salvaje sin remedio a su propio hijo. "My husband has never been much of an I'll push the stroller type daddy...", comenta Nancy. Por otra parte, Alan no censura su evidente misoginia: "You think too much. Women think too much", le dice a Penelope. Y ya en el clímax dramático, demuestra su desinterés por el conflicto y por el compromiso de Penelope:

I saw your friend Jane Fonda on TV the other day, made me wanna run out and buy a Ku Klux Klan poster [...]. You're the same breeze, the same kind of involved problem-solver woman, those are not the women we like, the women we like are sensual, crazy, shuffled over hormones. The gatekeepers of the world, the ones who wanna show off how perceptive they are... Huge turn off... (Polanski, dir., 2011)

Alan refleja una visión que no se aleja demasiado de los cuestionamientos que se hacía Polanski en What? Deja claro que, en su opinión, la mujer trabajadora carece de sensualidad y que el 
hombre siempre preferirá a la mujer objeto antes que a la mujer comprometida con su tiempo. Reza desvela aquí un punto clave que Polanski recoge con honestidad y tal vez con algo de autocrítica, que la emancipación de la mujer no ha sido ni respetada ni admitida por una amplia mayoría masculina. Sin embargo, y quizá de modo deliberado, Reza hace que Nancy (Annette en la obra), la más sumisa de las mujeres, tome la voz cantante y acabe desvelando las verdades más crueles: "I am glad our son kicked the shit out of your sun and I wipe my ass with your human rights!". A lo cual, Michael responde: "Wow! A couple of drinks in her and bam! The true self comes out. What happened to that gracious demure woman with the soft eyes?". Así, Nancy, como la Nancy de What?, la apocada y conciliadora esposa trofeo, acaba teniendo la revelación más sangrante, la más desnuda, de que todo es en el fondo una ficción, una charada de corrección política. Le planta cara a la misoginia paternalista de su marido y a los desplantes de superioridad moral de los padres del niño agredido.

Tal vez la mujer ya no sea muñeca, pero sigue a merced de su situación social con respecto al hombre. La mujer emancipada aún sucumbe ante el dios de las apariencias.

\section{El discreto encanto de las casas sin salida}

Volvamos a la casa. Para Roman Polanski, el hogar nunca ha dejado de ser ese universo hostil que ya ha sido mencionado, antítesis del refugio bachelardiano. Está la angustiosa villa de What?, un edén mucho más infernal de lo que parecía a primera vista, y de modo más explícito, el vecindario parisino de Le locataire (1976), y las paredes llenas de manos de Repulsion (1965). Por su parte, y de modo menos terrorífico aunque igualmente angustioso, Carnage se instala en el apartamento de los Longstreet sin jamás encontrar la salida, a pesar de los muchos intentos de los Cowan de huir de tantas verdades de las que responsabilizarse. El espacio viene descrito por la acotación de la obra original de este modo: "Règne un atmosphère grave, cordiale et tolérante" (Reza 2007: 9). La cordialidad se enturbia por la tensión e incomodidad palpables ya desde la primera escena. Si bien las funciones teatrales de la obra tendían a la sencillez y a la ausencia de detalles excesivamente naturalistas, Polanski aquí sí apuesta por una casa convencional, llena de elementos cotidianos que el espectador identifica con una casa "normal". En otra de las entrevistas, John C. Reilly (en Polanski 2012) admite que la precisión del decorado le ayudó a hacer suyo el personaje; meterse en la piel de Michael necesitaba que el actor pudiera ver y vivir su casa sin salida.

En principio vemos tan sólo las zonas comunes de la casa, estudio, salón y cocina (aunque en ésta estancia, los Cowan no llegan a entrar). La llegada de los visitantes ya resulta una incómoda 
incursión en su intimidad, en su refugio. Además, la visita de los Cowan ocurre bajo un pretexto ineludible, es decir, que no se trata de una invitación ni mucho menos amistosa. Por eso en principio sentimos mayor sensación de desnudez por parte de los Longstreet, intimidad que se ve vulnerada radicalmente en el momento en que ocurre el accidental vómito de Nancy y deben darles acceso a zonas más privadas, como son la habitación de matrimonio y el cuarto de baño. De hecho, Jodie Foster es capaz de revelar su patente incomodidad con un acertado gesto. Cuando guía a Alan hasta el baño, aprovecha para estirar velozmente la cama deshecha por el camino. Con el paso de los minutos, la intimidad va quedando completamente a la deriva. Penelope entra en el baño y pilla a Alan en ropa interior, y poco más que decir de la vergüenza que siente Nancy tras vomitar. Pero pronto no habrá tabúes sobre la mesa: los gritos, las lágrimas y la ebriedad dejarán todo al descubierto. Por mucho que se quiera, no hay modo de escapar, tanto What? como Carnage se encierran en sí mismas sin dar tregua a lo salvaje de nosotros mismos. No nos extraña que Cristoph Waltz considere que las casas sin salida son especialidad de Polanski:

I like movies that just play in a confined space. No, I wouldn't say this is Roman's specialty, but I've seen movies of Roman's that did play in confined spaces and they were fabulous. I don't whether I necessarily thought it was cinematic, but in connection with Roman's name, it certainly was. (Waltz, en Polanski 2012)

Ahora bien, Polanski también remite a otro de sus grandes maestros, Luis Buñuel. La ya citada El ángel exterminador (1962) es una indiscutible referencia, tanto de la caja de Pandora de Carnage, como de la villa godotiana de What? Precisamente, el aragonés estuvo muy activo en los años de rodaje de esta última, estrenando Belle de Jour (1967) y Tristana (1970), ambas interpretadas por Catherine Deneuve, la Carol de Repulsion (1965). Por otro lado está El discreto encanto de la burguesía, película paralela a What? y rodada precisamente en este año 1972. Ahora bien, volviendo al salvajismo sin salida de El ángel exterminador, nos parece interesante mencionar otro punto en común con Polanski. Recordemos que Noblart está a punto de adquirir una copia a tamaño natural de La Balsa de la medusa que dejará absorta a la Nancy de What?, quien preguntará, ingenuamente, si es el auténtico. Curiosamente, el hijo de Buñuel, respondiendo a las constantes búsquedas de significado que le pedían en relación a El ángel exterminador, comentaba que la película surgía precisamente del famoso lienzo de Géricault, que obsesionaba al maestro. 
No debe extrañar que este pintor fascinado por las fronteras de la conciencia (locos, ajusticiados, moribundos) interesara a Buñuel. Sus películas suelen manejar unas reducidas situaciones básicas, combinándolas de distintas formas [...]. El ángel exterminador no es sino el desarrollo monográfico de esa situación a la luz de La Balsa de la medusa de Géricault, pintura de la que surge la idea inicial del filme. (Sánchez Vidal 1984: 266)

De hecho, el título original iba a ser Los náufragos de la calle Providencia, queda claro que el salón sin salida es tan angustioso y dramático como la balsa de los náufragos de Géricault. ¿Es por tanto el de Polanski un homenaje a Buñuel? Tal vez. Lo que sí es evidente es que el director está reflexionando acerca de la copia. Noblart decidirá no adquirirlo porque ha abandonado el arte para volver a la vida: "Mr. Noblart has been more and more interested in life itself" (Polanski, dir., 1972). La copia casi exacta de la vida no es la vida, sino un cuadro, una ficción, una película.

Detrás de este desvelo, se esconde la loca sabiduría de Magritte con su Ceci n'est pas une pipe, todo era un juego producto de la ficción ${ }^{16}$. Como dice Avron, se trata de "una interrogación sobre la misma pintura $y$, por extensión, sobre el cine [...]" (Avron 1990: 128). Una reflexión sobre la ficción y un homenaje tanto a Buñuel como al mismo Magritte. "Polanski nos plantea un interrogante muy en la línea del Magritte de Ceci n'est pas une pipe [...] uno de los tópicos más socorridos del todo artista contemporáneo" (Moldes 2005: 258). Así pues, al estilo de Rivette, Fellini o Buñuel, Polanski abre los ojos del somnoliento espectador, acostumbrado al pacto de ficción convencional, y le recuerda que todo es un artificio, que esto no es una pipa, que esto tampoco es una casa. What? y Carnage son dos parábolas sobre el sentido de lo auténtico, y sobre el estatismo de la vida burguesa.

Aun así, la conclusión resulta mucho más pesimista, pues parece que los sueños (de ficción, de erotismo y de libertad) no han conseguido generar más que una sociedad de apariencias. Nancy ha crecido y ha cubierto su desnudez con la máscara de la conveniencia. La copia claramente ha vencido al cuerpo. De hecho, tal vez la inmovilidad de la sociedad sea la única moraleja detrás de estas casas sin salida. Godot sigue esperando, porque la sociedad no se ha movido: "El hecho es que, quiéranlo o no, la sociedad está inmovilizada. Creo que esa es la única interpretación simbólica que uno puede hacer", decía Juan Luis Buñuel (Sánchez Vidal 1984: 261). Tal vez no tengamos remedio. La mujer no ha conseguido dar su

16 Para una reflexión más profunda acerca del concepto de copia en la pintura de Magritte, resulta fundamental mencionar el ensayo de Michel Foucault (1981) Esto no es una pipa. 
paso definitivo, el tiempo no parece haber progresado. La casa nos ha paralizado y seguimos siendo náufragos de nosotros mismos.

¿La única salida? Un dios salvaje sin máscaras ni convencionalismos.

\section{Bibliografía}

AVRON, Dominique (1990): Roman Polanski. Barcelona: Edigraf.

BACHELARD, Gaston (2000): La poética del espacio. Traducción de Ernestina De Champourcin. México: Fondo de Cultura Económica.

BERGSON Henri (2011): La risa. Ensayo sobre la significación de la comicidad. Buenos Aires: Godot.

BUCI-GLUCKSMANN, Christine (1986): "Féminité et modernité: Walter Benjamin et I'utopie du fémenin", en Walter Benjamin et Paris, pp. 403-420. Paris: Les Éditions du Cerf.

BUCK-MORSS, Susan (1986): "Le flâneur, I'homme sandwich et la prostituée", en Walter Benjamin et Paris, pp. 361-402. Paris: Les Éditions du Cerf.

FEENEY, F. X.; y DUNCAN, Paul (eds.) (2006): Roman Polanski. Barcelona: Taschen.

FOUCAULT, Michel (1981): Esto no es una pipa. Madrid: Anagrama.

GAETANO, Roberto de (1999): Il corpo e la maschera. Il grottesco nel cinema italiano. Roma: Bulzoni editore.

GUYONNET, Damien (2010): "Images de la paranoia: Buñuel et Polanski". L'évolution psychiatrique, vol. 75, pp. 597-606.

ISENBERG, Noah; y WHITE, Rob (2012): "Carnage and all: a discussion". Film Quarterly, spring 2012, vol. 65, núm. 3.

LONGWORTH, Karina (2011): "White People problems in Roman Polanski's Carnage". The Village Voice, Wednesday, Dec 14.

MARTÍNEZ, Luis (2011): "El divertido y genial vómito de Polanski". El Mundo, 18/11/2011.

MOLDES, Diego (2005): Roman Polanski. La fantasía del atormentado. Madrid: Ediciones JC.

POLANSKI, Roman (1984): Roman by Polanski. New York: William Morrow and Company.

- (2012): "Entrevistas", en Un dios salvaje (Carnage). Edición especial con comentarios. Madrid: Cameo D.L.

REZA, Yasmina (2007): Le dieu du carnage. Paris: Albin Michel.

SANCHEZ VIDAL, Agustín (1984): Luis Buñuel, obra cinematográfica. Madrid: Ediciones JC.

SANDFORD, Christopher (2009): Polanski. Madrid: T\&B editores.

SHOR, Gabriele (ed.) (2013): Mujer/Woman. La vanguardia feminista de los años 70. Obras de la Sammlung Verbund, Viena. Madrid: Círculo de Bellas Artes.

STABLES, Kate (2012): "Carnage". Sight and Sound, vol. 22, núm. 2, feb. 2012, p. 62. 


\section{Filmografía}

BUÑUEL, Luis (dir.) (1962): El ángel exterminador. México: Producciones Gustavo Alatriste.

FERRERI, Marco (dir.) (1972): La cagna. (Título original: Liza). Italia: Pegaso cinematografica.

- (1973): La grande abbuffata. (Título original: La grande bouffe). Italia: Films 66.

POLANSKI, Roman (dir.) (1972): What? (Título original: Che?). Italia: Compagnia Cinematografica Champion.

- (2011): Un dios salvaje. (Título original: Carnage). España / Francia: SBS Productions.

- (2013): La Venus de las pieles. (Título original: La Venus à la Fourrure). Francia: R. P. Productions. 